\title{
Activation of Calcitonin Gene-Related Peptide and Adrenomedullin Receptors by PEGylated Adrenomedullin
}

\author{
Emiko Akashi, Sayaka Nagata,* Motoo Yamasaki, and Kazuo Kitamura \\ Circulatory and Body Fluid Regulation, Faculty of Medicine, University of Miyazaki; Kiyotake, Miyazaki 889-1692, \\ Japan. \\ Received April 27, 2020; accepted August 7, 2020
}

Adrenomedullin (AM) improves colitis in animal models and patients with inflammatory bowel disease. We have developed a PEGylated AM derivative (PEG-AM) for clinical application because AM has a short half-life in the blood. However, modification by addition of polyethylene glycol (PEG) may compromise the function of the original peptide. In this paper, we examined the time course of cAMP accumulation induced by 5 and $60 \mathrm{kDa}$ PEG-AM and compared the activation of calcitonin gene-related peptide (CGRP), AM1 and AM2 receptors by AM, 5 and $60 \mathrm{kDa}$ PEG-AM. We also evaluated the effects of antagonists on the action of 5 and $60 \mathrm{kDa}$ PEG-AM. PEG-AM stimulated cAMP production induced by these receptors; the increase in cAMP levels resulting from application of PEG-AM peaked at $15 \mathrm{~min}$. Moreover, PEG-AM activity was antagonized by CGRP (8-37) or AM (22-52) (antagonists of CGRP and AM receptors, respectively) and the maximal response was not suppressed. These findings indicate that the effects of PEG-AM are similar to those of native AM.

Key words adrenomedullin; calcitonin gene-related peptide; polyethylene glycol; receptor activity-modifying protein; calcitonin receptor-like receptor; inflammatory bowel disease

\section{INTRODUCTION}

Adrenomedullin (AM) comprises 52 amino acids and belongs to the calcitonin family, which includes calcitonin, calcitonin gene-related peptide (CGRP), amylin and adrenomedullin 2. ${ }^{1,2)}$ Among them, AM shares 24\% homology with and has similar biological activity to CGRP. ${ }^{3}$

The members of this family share a ring structure formed by an intramolecular disulfide bond and a C-terminal amide structure. These two sites are necessary for receptor binding and signaling. ${ }^{4,5)}$ CGRP (8-37) is a known antagonist of the CGRP receptor and AM (22-52) is an antagonist of AM1 and AM2 receptors. ${ }^{6,7)}$

AM exhibits various physiological effects such as vasodilation, anti-inflammation, angiogenesis, antioxidation and wound healing effects. ${ }^{8)}$ Our group previously demonstrated that AM improved colitis in animal models. ${ }^{9}$ AM significantly reduced the severity of colitis, increased body weight and suppressed secretion of inflammatory cytokines. ${ }^{10)}$ Therefore, we conducted a clinical study in patients with inflammatory bowel disease (IBD). ${ }^{11,12)}$ However, in these studies, long-term intravenous infusion of AM was necessary because it has a half-life of approximately $20 \mathrm{~min}^{13)}$ To overcome this issue, we investigated AM derivatives to increase the half-life of AM.

PEGylation is generally considered a method of extending the half-life of substances in the blood. ${ }^{14)}$ Polyethylene glycol (PEG) modification delays excretion from the kidney, prolongs residence time in the blood and can reduce the dose and frequency of administration.

Therefore, we developed a PEGylated AM derivative (PEG$\mathrm{AM}$ ), which is conjugated with 5 and $60 \mathrm{kDa}$ PEG at the $\mathrm{N}$-terminus of AM so that structures important for its activity are not affected. ${ }^{15,16)}$ After the subcutaneous injection of 5 and $60 \mathrm{kDa}$ PEG-AM, they were still observed in the blood at a measurable concentration after $3 \mathrm{~h}$ and on the tenth day, respectively. However, AM had disappeared after 2 h. ${ }^{17)}$ Additionally, PEG-AM maintained the pharmaceutical effects in a dextran sodium sulfate (DSS)-induced colitis model.

$\mathrm{AM}$ binds to calcitonin receptor-like receptor (CLR), a seven-transmembrane $\mathrm{G}$ protein-coupled receptor that is coexpressed with receptor activity-modifying protein (RAMP)1, -2 or $-3{ }^{18)}$ RAMPs are single membrane receptors that transport CLR to the cell surface and regulate its expression. CLR/ RAMP1 functions as a CGRP receptor and CLR/RAMP2 or -3 functions as an AM1 or AM2 receptor. ${ }^{19,20)}$ AM activates adenylate cyclase through these receptors and produces intracellular cAMP.

We showed the effects of 5 and $60 \mathrm{kDa}$ PEG-AM in a DSSinduced colitis model, while the effects of 5 and $60 \mathrm{kDa}$ PEGAM on CGRP and AM receptors are unknown. PEGylation may hinder the original activity of the peptide; therefore, it is important to evaluate activity of PEGylated drugs.

In the present study, to assess the activity of PEG-AM, we determined the intracellular cAMP levels in human embryonic kidney (HEK)-293 cells stably expressing CGRP, AM1 and AM2 receptors.

\section{MATERIALS AND METHODS}

Peptide Preparation AM (1-52), 5 kDa PEG-AM, CGRP, CGRP (8-37) and AM (22-52) were purchased from Peptide Institute Inc. (Osaka, Japan). The $60 \mathrm{kDa}$ PEG-AM used in this study was synthesized as reported previously. ${ }^{16}$

Cell Culture We used HEK-293 cells stably expressing CLR/RAMP1 (CGRP), CLR/RAMP2 (AM1) or CLR/ RAMP3 (AM2) receptors that had been prepared as previously described. ${ }^{20)}$ These cells were maintained under standard cell culture conditions in Dulbecco's modified Eagle's 
A

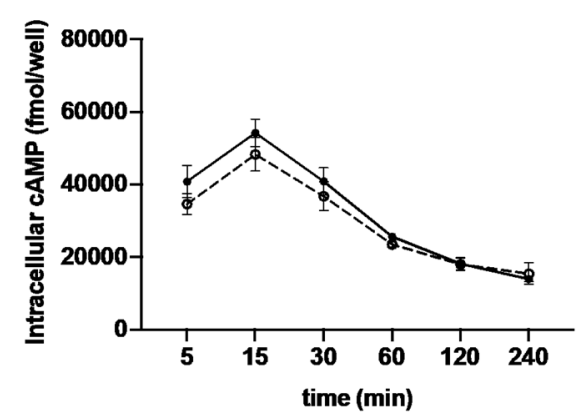

B

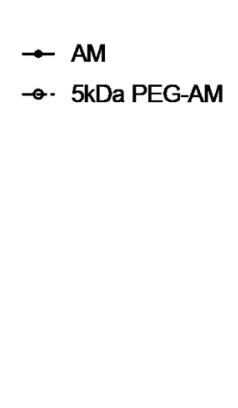

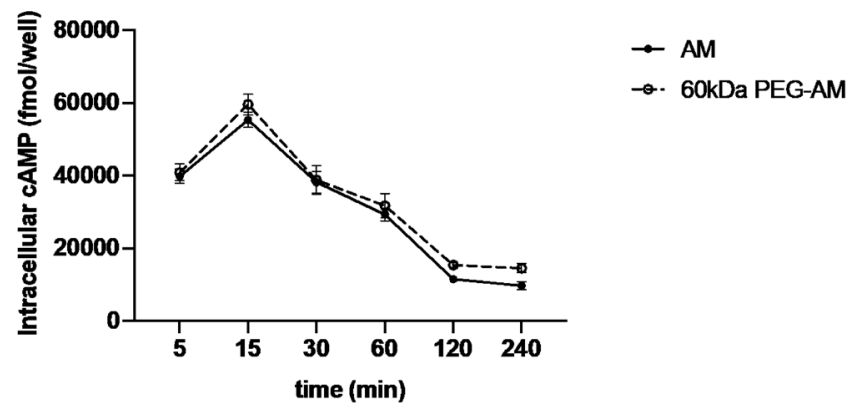

Fig. 1. Time Course of cAMP Accumulation in Response to AM and PEG-AM in HEK-293 Cells Stably Expressing the AM1 Receptor

(A) A time course of cAMP formation in response to $0.1 \mu \mathrm{M}$ AM and $0.1 \mu \mathrm{M} 5 \mathrm{kDa}$ PEG-AM in HEK-293 cells stably expressing the AM1 receptor. (B) A time course of cAMP formation in response to $0.1 \mu \mathrm{M}$ AM and $10 \mu \mathrm{M} 60 \mathrm{kDa}$ PEG-AM in HEK-293 cells stably expressing the AM1 receptor. The data represent the mean \pm standard deviation of six samples.

A

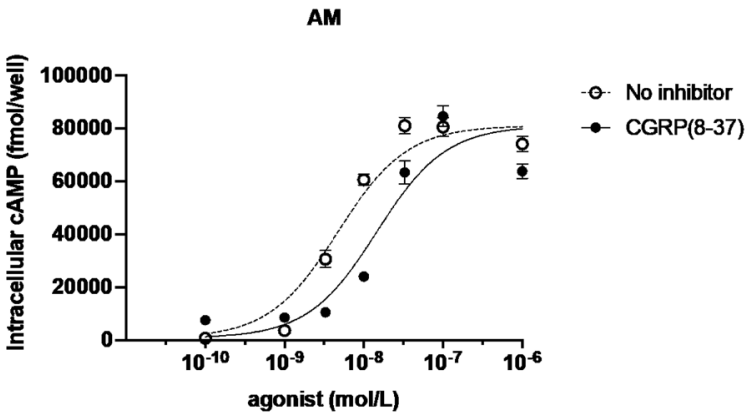

B

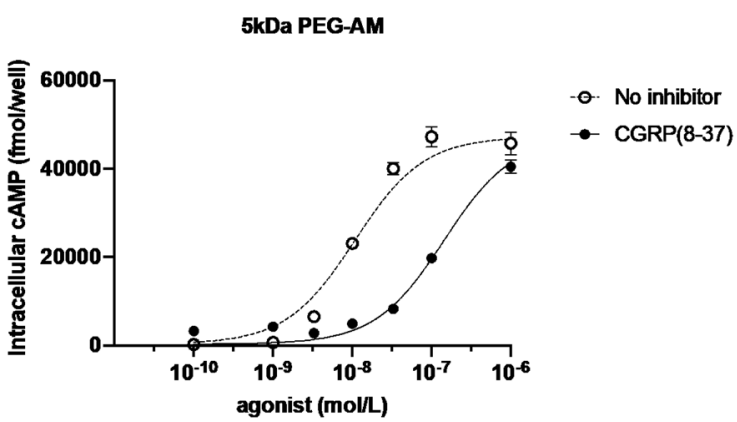

C

60kDa PEG-AM

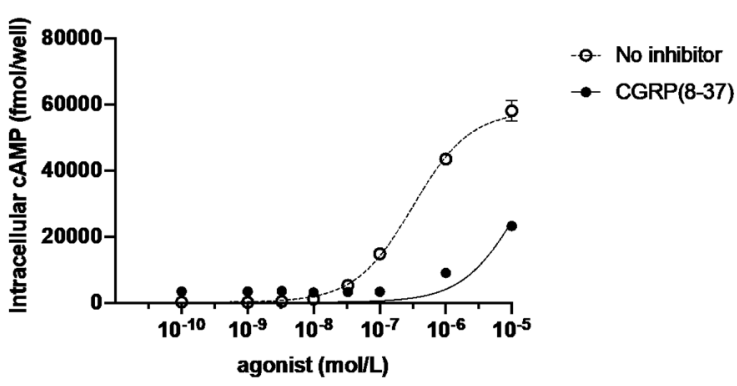

Fig. 2. Effect of CGRP (8-37) on Agonist-Induced cAMP Production in HEK-293 Cells Stably Expressing the CGRP Receptor

cAMP responses to AM (A), $5 \mathrm{kDa}$ PEG-AM (B) or $60 \mathrm{kDa}$ PEG-AM (C) in cells expressing the CGRP receptor, with or without $0.1 \mu \mathrm{M}$ CGRP (8-37) treatment. The data represent the mean \pm standard error of four samples.

medium with $10 \%$ fetal bovine serum, 100 units $/ \mathrm{mL}$ penicillin, $100 \mu \mathrm{g} / \mathrm{mL}$ streptomycin, $0.25 \mu \mathrm{g} / \mathrm{mL}$ amphotericin $\mathrm{B}$, $100 \mu \mathrm{g} / \mathrm{mL}$ hygromycin $\mathrm{B}$ and $250 \mu \mathrm{g} / \mathrm{mL}$ geneticin at $37^{\circ} \mathrm{C}$ in a humidified atmosphere of $95 \%$ air and $5 \% \mathrm{CO}_{2}$.

cAMP Assay To examine cAMP accumulation, HEK-293 cells were seeded at $2.0 \times 10^{4}$ cells/well in Dulbecco's modified Eagle's medium containing $10 \%$ fetal bovine serum without antibiotics on 24-well plates coated with human fibronectin. After culturing for $3 \mathrm{~d}$, cells at $70-80 \%$ confluency were subjected to experiments. The cells were preincubated for $5 \mathrm{~min}$ at $37^{\circ} \mathrm{C}$ with Hanks' Balanced Salt Solution containing $0.2 \%$ bovine serum albumin, $0.035 \% \mathrm{NaHCO}_{3}$ and $0.5 \mathrm{mM}$ isobutylmethylxanthine with or without an antagonist before exposure to $\mathrm{AM}, 5$ or $60 \mathrm{kDa}$ PEG-AM. ${ }^{21)}$ The incubation time was $15 \mathrm{~min}$, except for the time course experiment. The reactions were terminated by the addition of a lysis reagent. Intracellular cAMP values were determined using an enzyme immunoassay kit (GE Healthcare UK Limited, U.K.).
Statistical Analysis The time course data are presented as the means \pm standard deviation of six samples. cAMP assay data are expressed as the means \pm standard error of four samples. Statistical analysis was performed using the Gaddum/ Schild $50 \%$ effective concentration $\left(\mathrm{EC}_{50}\right)$ shift equation in GraphPad Prism 8 (GraphPad Software, La Jolla, CA, U.S.A.).

\section{RESULTS}

Time Course of cAMP Accumulation in Response to AM, 5 or $60 \mathrm{kDa}$ PEG-AM in HEK-293 Cells Stably Expressing the AM1 Receptor As shown in Fig. 1, the cAMP level was significantly increased at $5 \mathrm{~min}$ and peaked at $15 \mathrm{~min}$ after application of $0.1 \mu \mathrm{M}$ AM, $0.1 \mu \mathrm{M} 5 \mathrm{kDa}$ PEG-AM or $10 \mu \mathrm{M} 60 \mathrm{kDa}$ PEG-AM in HEK-293 cells stably expressing the AM1 receptor. Then, the cAMP levels gradually decreased.

Effect of CGRP (8-37) on Agonist-Induced cAMP Pro- 
A

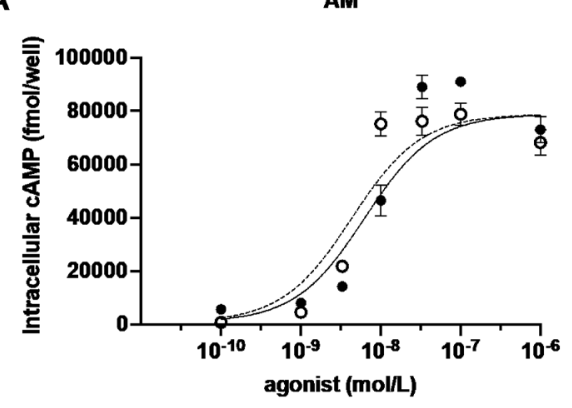

B

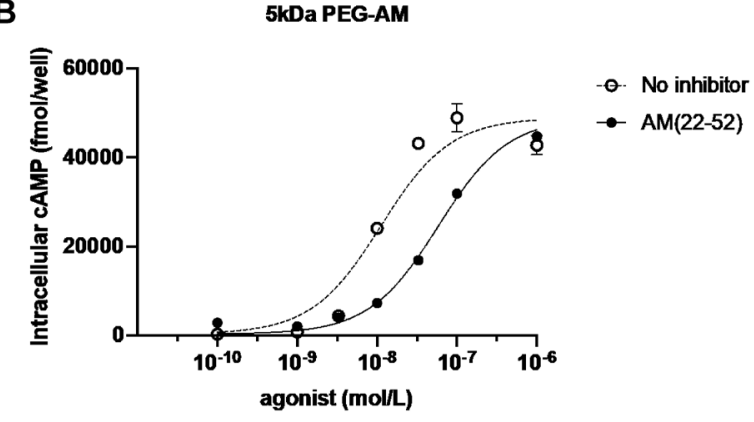

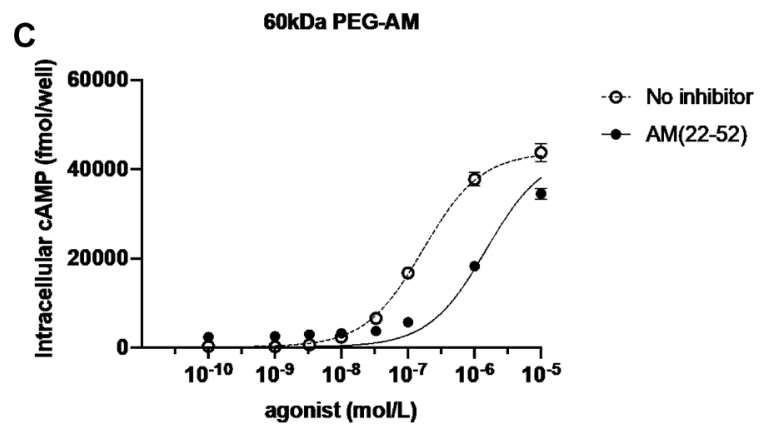

Fig. 3. Effect of AM (22-52) on Agonist-Induced cAMP Production in HEK-293 Cells Stably Expressing the AM1 Receptor

cAMP responses to AM (A), $5 \mathrm{kDa}$ PEG-AM (B) or $60 \mathrm{kDa}$ PEG-AM (C) in cells expressing the AM1 receptor, with or without $10 \mu \mathrm{M}$ AM (22-52) treatment. The data represent the mean \pm standard error of four samples.
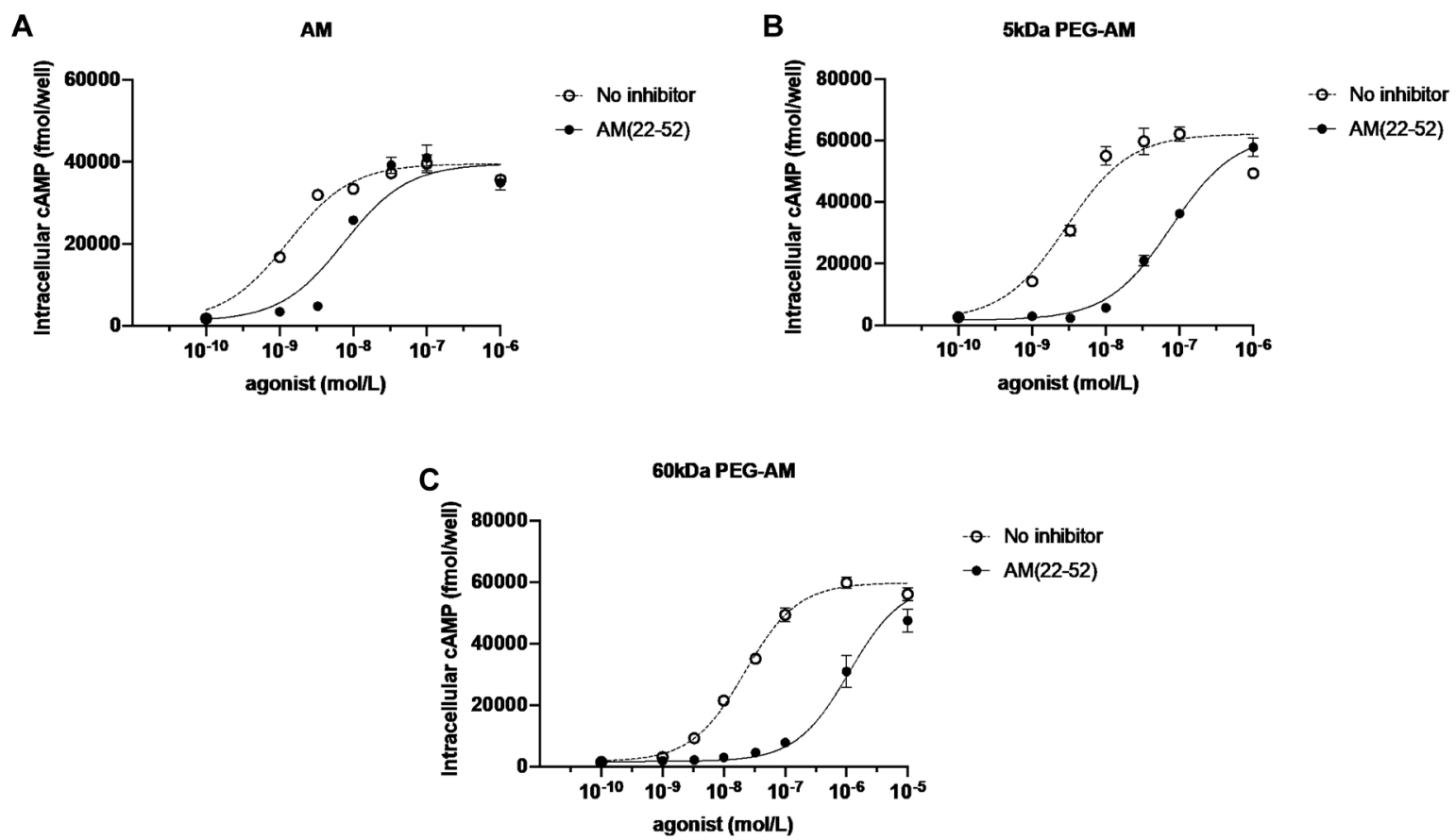

Fig. 4. Effect of AM (22-52) on Agonist-Induced cAMP Production in HEK-293 Cells Stably Expressing the AM2 Receptor

cAMP responses to AM (A), $5 \mathrm{kDa}$ PEG-AM (B) or $60 \mathrm{kDa}$ PEG-AM (C) in cells expressing the AM2 receptor, with or without $10 \mu \mathrm{M}$ AM (22-52) treatment. The data represent the mean \pm standard error of four samples.

duction in HEK-293 Cells Stably Expressing the CGRP Receptor As shown in Fig. 2, we examined the effect of the antagonist CGRP (8-37) $(0.1 \mu \mathrm{M})$ on intracellular cAMP production induced by AM, 5 or $60 \mathrm{kDa}$ PEG-AM in HEK-293 cells stably expressing the CGRP receptor. The $-\log \mathrm{EC}_{50}\left(\mathrm{pEC}_{50}\right)$ values of $\mathrm{AM}, 5$ and $60 \mathrm{kDa}$ PEG-AM were $8.32 \pm 0.07,7.97 \pm 0.04$ and $6.50 \pm 0.04$, respectively (Figs. 2A-C). CGRP (8-37) produced a rightward displacement of the curve in response to the agonists without depression of the maximal response. The effects of AM, 5 and $60 \mathrm{kDa}$ PEG-AM were inhibited by CGRP (8-37), with pA2 values of $7.32 \pm 0.14,8.09 \pm 0.07$ and $8.63 \pm 0.06$, respectively (Figs. $2 \mathrm{~A}-\mathrm{C})$.

Effect of AM (22-52) on Agonist-Induced cAMP Production in HEK-293 Cells Stably Expressing the AM1 Receptor As shown in Fig. 3, we examined the effect of 
the antagonist AM (22-52) $(10 \mu \mathrm{M})$ on intracellular cAMP production induced by AM, 5 or $60 \mathrm{kDa}$ PEG-AM in HEK-293 cells stably expressing the AM1 receptor. The $\mathrm{pEC}_{50}$ values of $\mathrm{AM}, 5$ and $60 \mathrm{kDa}$ PEG-AM were $8.36 \pm 0.10,7.95 \pm 0.05$ and $6.78 \pm 0.04$, respectively (Figs. 3A-C). AM (22-52) produced a rightward displacement of the curve in response to the agonists without depression of the maximal response. The effects of AM, 5 and $60 \mathrm{kDa}$ PEG-AM were inhibited by AM (22-52) with pA2 values of $4.65 \pm 0.45,5.63 \pm 0.09$ and $5.90 \pm 0.07$, respectively (Figs. 3A-C).

Effect of AM (22-52) on Agonist-Induced cAMP Production in HEK-293 Cells Stably Expressing the AM2 Receptor As shown in Fig. 4, we examined the effect of the antagonist AM (22-52) $(10 \mu \mathrm{M})$ on intracellular cAMP production induced by AM, 5 or $60 \mathrm{kDa}$ PEG-AM in HEK-293 cells stably expressing the AM2 receptor. The $\mathrm{pEC}_{50}$ values of $\mathrm{AM}, 5$ and $60 \mathrm{kDa}$ PEG-AM were $8.89 \pm 0.07,8.54 \pm 0.05$ and $7.66 \pm 0.04$, respectively (Figs. 4A-C). AM (22-52) produced a rightward displacement of the curve in response to the agonists without depression of the maximal response. The effects of AM, 5 and $60 \mathrm{kDa}$ PEG-AM were inhibited by AM (22-52) with pA2 values of $5.68 \pm 0.12,6.41 \pm 0.08$ and $6.70 \pm 0.07$, respectively (Figs. 4A-C).

\section{DISCUSSION}

In this study, to understand the properties of PEG-AM, a long-acting AM derivative, we assessed its activity and the effects of antagonists in HEK-293 cells stably expressing CGRP, AM1 and AM2 receptors.

To investigate whether the increased stability of PEG-AM leads to prolonged receptor activation, the time course of cAMP accumulation after application of AM, 5 and $60 \mathrm{kDa}$ PEG-AM was compared in cells expressing AM1 receptors. In this experiment, the concentrations of AM, 5 and $60 \mathrm{kDa}$ PEG-AM were $0.1,0.1$, and $10 \mu \mathrm{M}$, respectively. Each concentration produced a maximum response of the AM1 receptor. These data indicated that intracellular cAMP production in response to 5 and $60 \mathrm{kDa}$ PEG-AM peaked at $15 \mathrm{~min}$ in cells expressing the AM1 receptor, similar to the results found for the AM. This result is similar to those of previous studies using cultured rat cardiac myocytes and nonmyocytes. ${ }^{22}$ Regarding cAMP production, the behavior of PEG-AM has been shown to be similar to that of AM when it binds to receptors and exerts its effects. According to the time course experiment, $15 \mathrm{~min}$ was determined to be the reaction time in the cAMP assay in HEK-293 cells stably expressing CGRP, AM1 and AM2 receptors.

For AM1 or AM2 receptors, which are the main subtypes of AM receptors, we observed that 5 and $60 \mathrm{kDa}$ PEG-AM increased the intracellular cAMP levels in a concentrationdependent manner. Moreover, 5 and $60 \mathrm{kDa}$ PEG-AM showed maximal activity similar to that of native AM at high concentrations. These results suggested that a high concentration of PEG-AM exerts actions similar to those of AM. Because AM exerts rapid vasodilation activity, it must be infused continuously with careful dose settings in human patients with IBD. Intravenous bolus infusion of $10 \mathrm{nmol} / \mathrm{kg}$ AM produced an acute hypotensive effect, while the same dose of $5 \mathrm{kDa}$ PEG-AM reduced the acute hypotensive effect. ${ }^{15)}$ Therefore, PEG-AM is expected to reduce side effects, such as headache caused by vasodilation, when used for IBD treatment. Additionally, the activity of 5 and $60 \mathrm{kDa}$ PEG-AM were blocked by AM (22-52) without suppressing the maximal response. PEG-AM exhibited decreased affinity for its receptors as the molecular weight of PEG increased. Accordingly, the antagonistic effect of AM (22-52) was increased in proportion to the molecular weight of PEG.

We observed that 5 and $60 \mathrm{kDa}$ PEG-AM increased the intracellular cAMP levels in a concentration-dependent manner in cells expressing the CGRP receptor. This response was easily antagonized by CGRP (8-37) without suppressing the maximal response. The $\mathrm{pEC}_{50}$ of CGRP was $9.76 \pm 0.07$ (data not shown). This value was larger than that of AM because AM binds to the CGRP receptor with lower affinity than that for AM1 and AM2 receptors and CGRP (8-37) can bind to the CGRP receptor with an affinity comparable to that for CGRP. ${ }^{2,18,23,24)}$

In animal experiment, the maximum drug concentrations of AM and $60 \mathrm{kDa}$ PEG-AM were 10 and $2000 \mathrm{pM}$, respectively. ${ }^{17)}$ Furthermore, daily injections of $80 \mathrm{nmol} / \mathrm{kg}$ AM are necessary to treat DSS-induced colitis in mice, but a single injection of $25 \mathrm{nmol} / \mathrm{kg} 60 \mathrm{kDa}$ PEG-AM improved the same model. ${ }^{25)}$ PEG-AM is more useful because the dose and frequency of administration are reduced, which improves the QOL.

Before we evaluated the activities of 5 and $60 \mathrm{kDa}$ PEGAM, we preliminary confirmed that they were stable for at least $6 \mathrm{~d}$ when stored in polypropylene tubes at room temperature (data not shown). Additionally, 5 and $60 \mathrm{kDa}$ PEG-AM seem to be stable at $-30^{\circ} \mathrm{C}$ for more than 3 years, because they show compatible chromatographic pattern on gel-filtration chromatography. The long-term storage tests for $\mathrm{AM}$ and PEG-AM formula are in progress. It is well known that PEGylation improve the stability of biologically active peptides. $^{14)}$

We showed that $60 \mathrm{kDa}$ PEG-AM prevented memory disturbances and learning disabilities in four-vessel occlusion model rats. $^{26)}$ Because PEG-AM activates the CGRP, AM1 and AM2 receptors that are expressed in various tissues, ${ }^{27)}$ PEG-AM may be used not only as a therapeutic agent for IBD but also as a therapeutic agent targeting other tissues.

In conclusion, we demonstrated that PEG-AM activated the AM1 receptor as well as CGRP and AM2 receptors. Furthermore, we discovered that antagonists blocked the increase in cAMP production induced by PEG-AM. Both effects were as similar to those of native AM and the addition of PEG did not influence the receptor selectivity. Although the effect of PEG-AM has not been established in vivo, we believe that the current study could contribute to an improved understanding of this effect.

Acknowledgments This work was partly supported by a Grant-in-Aid for Scientific Research from the Japan Society for the Promotion of Science (Grant number: 18H02810) and a Scientific Research Grant for Creating Start-ups from Advanced Research and Technology (START Program) from the Japan Science and Technology Agency (Grant number: ST262010WV).

Conflict of Interest The authors declare that K. Kitamura, M. Yamasaki and S. Nagata have stock in Himuka 
AM Pharma Corporation.

\section{REFERENCES}

1) Kitamura $K$, Kangawa $K$, Kawamoto $M$, Ichiki $Y$, Nakamura $S$, Matsuo H, Eto T. Adrenomedullin: a novel hypotensive peptide isolated from human pheochromocytoma. Biochem. Biophys. Res. Commun., 192, 553-560 (1993).

2) Hay DL, Garelja ML, Poyner DR, Walker CS. Update on the pharmacology of calcitonin/CGRP family of peptides: IUPHAR Review 25. Br. J. Pharmacol., 175, 3-17 (2018).

3) Wimalawansa SJ. Amylin, calcitonin gene-related peptide, calcitonin, and adrenomedullin: a peptide superfamily. Crit. Rev. Neurobiol., 11, 167-239 (1997).

4) Conner AC, Hay DL, Howitt SG, Kilk K, Langel U, Wheatley M, Smith DM, Poyner DR. Interaction of calcitonin-gene-related peptide with its receptors. Biochem. Soc. Trans., 30, 451-455 (2002).

5) Kitamura K, Sakata J, Kangawa K, Kojima M, Matsuo H, Eto T. Cloning and characterization of cDNA encoding a precursor for human adrenomedullin. Biochem. Biophys. Res. Commun., 194, 720-725 (1993).

6) Eguchi S, Hirata Y, Iwasaki H, Sato K, Watanabe TX, Inui T, Nakajima K, Sakakibara S, Marumo F. Structure-activity relationship of adrenomedullin, a novel vasodilatory peptide, in cultured rat vascular smooth muscle cells. Endocrinology, 135, 2454-2458 (1994).

7) Chiba T, Yamaguchi A, Yamatani T, Nakamura A, Morishita T, Inui T, Fukase M, Noda T, Fujita T. Calcitonin gene-related peptide receptor antagonist human CGRP-(8-37). Am. J. Physiol., 256, E331E335 (1989).

8) Kato J, Kitamura K. Bench-to-bedside pharmacology of adrenomedullin. Eur. J. Pharmacol., 764, 140-148 (2015).

9) Ashizuka S, Ishikawa N, Kato J, Yamaga J, Inatsu H, Eto T, Kitamura K. Effect of adrenomedullin administration on acetic acidinduced colitis in rats. Peptides, 26, 2610-2615 (2005).

10) Hayashi Y, Narumi K, Tsuji S, Tsubokawa T, Nakaya MA, Wakayama T, Zuka M, Ohshima T, Yamagishi M, Okada T. Impact of adrenomedullin on dextran sulfate sodium-induced inflammatory colitis in mice: insights from in vitro and in vivo experimental studies. Int. J. Colorectal Dis., 26, 1453-1462 (2011).

11) Ashizuka S, Inatsu H, Kita T, Kitamura K. Adrenomedullin therapy in patients with refractory ulcerative colitis: a case series. Dig. Dis. Sci., 61, 872-880 (2016).

12) Ashizuka S, Kuroishi N, Nakashima K, Inatsu H, Kita T, Kitamura K. Adrenomedullin: a novel therapy for intractable Crohn's disease with a loss of response to infliximab. Intern. Med., 58, 1573-1576 (2019).

13) Meeran K, O'Shea D, Upton PD, Small CJ, Ghatei MA, Byfield PH, Bloom SR. Circulating adrenomedullin does not regulate systemic blood pressure but increases plasma prolactin after intravenous infusion in humans: a pharmacokinetic study. J. Clin. Endocrinol. Metab., 82, 95-100 (1997).
14) Knop K, Hoogenboom R, Fischer D, Schubert US. Poly(ethylene glycol) in drug delivery: pros and cons as well as potential alternatives. Angew. Chem. Int. Ed. Engl., 49, 6288-6308 (2010).

15) Kubo K, Tokashiki M, Kuwasako K, Tamura M, Tsuda S, Kubo S, Yoshizawa-Kumagaye K, Kato J, Kitamura K. Biological properties of adrenomedullin conjugated with polyethylene glycol. Peptides, 57, 118-121 (2014).

16) Nagata S, Yamasaki M, Kitamura K. Anti-inflammatory effects of PEGylated human adrenomedullin in a mouse DSS-induced colitis model. Drug Dev. Res., 78, 129-134 (2017).

17) Nishimoto Y, Nagata S, Akashi E, Yamasaki M, Kitamura K. Thrombin rapidly digests adrenomedullin: synthesis of adrenomedullin analogs resistant to thrombin. Biochem. Biophys. Res. Commun., 529, 778-783 (2020).

18) McLatchie LM, Fraser NJ, Main MJ, Wise A, Brown J, Thompson $\mathrm{N}$, Solari R, Lee MG, Foord SM. RAMPs regulate the transport and ligand specificity of the calcitonin-receptor-like receptor. Nature, 393, 333-339 (1998).

19) Muff R, Leuthäuser K, Bühlmann N, Foord SM, Fischer JA, Born $\mathrm{W}$. Receptor activity modifying proteins regulate the activity of a calcitonin gene-related peptide receptor in rabbit aortic endothelial cells. FEBS Lett., 441, 366-368 (1998).

20) Kuwasako K, Shimekake Y, Masuda M, Nakahara K, Yoshida T, Kitaura M, Kitamura K, Eto T, Sakata T. Visualization of the calcitonin receptor-like receptor and its receptor activity-modifying proteins during internalization and recycling. J. Biol. Chem., 275, 29602-29609 (2000).

21) Nagoshi Y, Kuwasako K, Ito K, Uemura T, Kato J, Kitamura K, Eto $\mathrm{T}$. The calcitonin receptor-like receptor/receptor activity-modifying protein 1 heterodimer can function as a calcitonin gene-related peptide-(8-37)-sensitive adrenomedullin receptor. Eur. J. Pharmacol., 450, 237-243 (2002).

22) Nishikimi T, Horio T, Yoshihara F, Nagaya N, Matsuo H, Kangawa $\mathrm{K}$. Effect of adrenomedullin on cAMP and cGMP levels in rat cardiac myocytes and nonmyocytes. Eur. J. Pharmacol., 353, 337-344 (1998).

23) Kuwasako K, Cao YN, Nagoshi Y, Kitamura K, Eto T. Adrenomedullin receptors: pharmacological features and possible pathophysiological roles. Peptides, 25, 2003-2012 (2004).

24) Bailey RJ, Hay DL. Pharmacology of the human CGRP1 receptor in Cos 7 cells. Peptides, 27, 1367-1375 (2006).

25) Kinoshita Y, Arita S, Murazoe H, Kitamura K, Ashizuka S, Inagaki-Ohara K. Subcutaneously administered adrenomedullin exerts a potent therapeutic effect in a murine model of ulcerative colitis. Hum. Cell, 32, 12-21 (2019).

26) Nagata S, Yamasaki M, Kitamura K. Polyethylene glycol-conjugated human adrenomedullin as a possible treatment for vascular dementia. Peptides, 121, 170133 (2019).

27) Hay DL, Smith DM. Adrenomedullin receptors: molecular identity and function. Peptides, 22, 1753-1763 (2001). 